\title{
The development of a banded microstructure in S355J2 steel bar
}

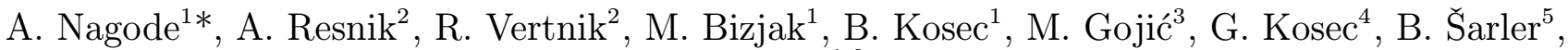 \\ B. $\operatorname{Zorc}^{1,6}$ \\ ${ }^{1}$ University of Ljubljana, Faculty of Natural Sciences and Engineering, Aškerčeva cesta 12, SI - 1000 Ljubljana, Slovenia \\ ${ }^{2}$ Store Steel d.o.o., Store, Slovenia \\ ${ }^{3}$ University of Zagreb, Faculty of Metallurgy, Sisak, Croatia \\ ${ }^{4}$ Acroni d.o.o., Jesenice, Slovenia \\ ${ }^{5}$ University of Nova Gorica, Laboratory for Multiphase Processes, Nova Gorica, Slovenia \\ ${ }^{6}$ Institut za varilstvo d.o.o., Ljubljana, Slovenia
}

Received 13 February 2015, received in revised form 12 March 2015, accepted 8 February 2016

\begin{abstract}
A homogeneous microstructure plays an important role in the mechanical properties of every alloy. However, because of chemical inhomogeneities, a banded microstructure can develop in steels. This banding has a negative effect, especially on the impact toughness and cold forming. In this paper, the development of a banded microstructure in hot-rolled low-alloy structural steel S355J2 is explained. The banded microstructure in the cross-section consisted of ferrite and pearlite bands, while towards the centre, bainitic-martensitic bands were also observed. The deviations in chemical compositions of the bands were measured with EDS, which showed that the bainitic-martensitic bands contained more alloying elements ( $\mathrm{Mn}, \mathrm{Cr}, \mathrm{Mo}, \mathrm{Si})$ than the ferritic. However, by using Oberhoffer reagent, the segregations of phosphorus were also revealed. Phosphorus segregations coincided with the positive segregations of the alloying elements. Because manganese and chromium have the prevailing effect on the distribution of carbon in austenite, an increased concentration of carbon in bainitic-martensitic bands is also expected. The CCT diagrams of S355J2 steel with three different chemical compositions, i.e., with the nominal composition and compositions with negative and positive segregations, were calculated. However, increased concentrations of carbon and phosphorus were not taken into account in the calculations of the CCT diagrams. Since these elements can significantly increase the hardenability, they play an important role in the formation of the bainite and martensite.
\end{abstract}

Key words: S355J2 steel, banded microstructure, phosphorus segregations, Oberhoffer reagent, CCT diagrams

\section{Introduction}

The mechanical properties of steels are dependent on their microstructure and the associated defects. The chemical inhomogeneities in the microstructure due to the inter-dendritic (micro) segregations of the alloying elements, as well as carbon and phosphorus, can cause the development of a banded microstructure. This form of microstructure consists of alternating bands of different microstructural constituents aligned parallel to the rolling direction of steel products. The presence of inter-dendritic segregations does not necessarily lead to the development of microstructural banding; its occurrence also strongly depends on the austenite crystal grain size and, especially, on the cooling conditions from the austenite region. A banded microstructure can also be observed in steels with a high content of manganese sulphide inclusions [1-4]. Elongated inclusions and a banded microstructure have a negative effect on the impact properties in both the longitudinal and transverse directions. If the banded microstructure also consists of martensite bands, it is detrimental to any machining and subsequent cold-forming operations $[2,5]$.

*Corresponding author: tel: +386 12000 433; fax: +386147045 60; e-mail address: ales.nagode@omm.ntf.uni-lj.si 
Ta ble 1. Nominal chemical composition of the S355J2 steel (wt.\%)

\begin{tabular}{cccccccccccccc}
\hline $\mathrm{C}$ & $\mathrm{Si}$ & $\mathrm{Mn}$ & $\mathrm{P}$ & $\mathrm{S}$ & $\mathrm{Cr}$ & $\mathrm{Mo}$ & $\mathrm{Ni}$ & $\mathrm{Al}$ & $\mathrm{Cu}$ & $\mathrm{Nb}$ & $\mathrm{B}$ & $\mathrm{Fe}$ \\
\hline 0.18 & 0.28 & 1.38 & 0.012 & 0.013 & 0.13 & 0.03 & 0.11 & 0.026 & 0.17 & 0.001 & 0.0006 & $\mathrm{Bal}$. \\
\hline
\end{tabular}

Besides banding, the phosphorus in steel can cause quench cracking and quench embrittlement and thus, it is very harmful, especially when is not homogeneously distributed [6]. Since the overall concentration of phosphorus in steel is usually very low, the measurement of phosphorus inhomogeneities in the microstructure is challenging because of low detection limits of conventional analytical techniques based on X-ray spectroscopy (EDS, WDS). Thus, phosphorus segregation can be easily overlooked. Hence, it is essential to understand the primary reasons for the development of microstructural banding in order to take appropriate actions so as to minimise its occurrence and deleterious effects, especially with respect to coldforming processes and quenching.

\section{Experimental procedure}

\subsection{Material}

The banding microstructure was investigated in a low-alloy structural steel S355J2. This steel, with a nominal chemical composition listed in Table 1, has a minimum yield strength of $355 \mathrm{~N} \mathrm{~mm}^{-2}$ and is used mainly for the production of cold-formed sections. The investigated steel was supplied as a hot-rolled bar with a diameter of $65 \mathrm{~mm}$. The rolling process under industrial conditions began at $1200^{\circ} \mathrm{C}$ and ended at $875^{\circ} \mathrm{C}$.

\subsection{Hot-rolling and temperature measurements}

The temperature of the steel bar after hot rolling was measured with a digital, two-colour pyrometer M90R-1 and a thermal camera FLIR ThermoVision SC6000HS with the software package ThermaCAM Research Pro2.8 SR-3 in order to obtain the cooling curve. The pyrometer was used for measuring the temperature after hot rolling down to $700^{\circ} \mathrm{C}$. The temperatures below $700^{\circ} \mathrm{C}$ were measured with a thermal camera.

\subsection{Microstructure characterisation}

The samples for the microstructure characterisation were cut from the hot-rolled steel bar in such a way that the normal to the sample surface was parallel to the axis of the bar. The samples were metallographically prepared, i.e., ground with abrasive paper to 1200 grit and then diamond polished, first with a particle size of $3 \mu \mathrm{m}$ and then with a particle size of $1 \mu \mathrm{m}$. After the polishing, the samples were etched with $2 \%$ Nital. However, in order to reveal the phosphorus segregation, the samples needed to be etched with Oberhoffer reagent $(500 \mathrm{ml}$ of distilled water, $500 \mathrm{ml} \mathrm{C}_{2} \mathrm{H}_{5} \mathrm{OH}, 50 \mathrm{ml} \mathrm{HCl}, 30 \mathrm{~g} \mathrm{FeCl}_{3}, 1 \mathrm{~g} \mathrm{CuCl}_{2}$, $0.5 \mathrm{~g} \mathrm{SnCl}_{2}$ ) [7].

The microstructure analyses were performed with a light (LM) and scanning electron microscope (SEM), i.e., Olympus BX61 and Jeol JSM 5610, respectively. The microstructure was observed in secondary electron mode (SEI) with an accelerating voltage of 20 $\mathrm{kV}$ and a working distance of $20 \mathrm{~mm}$. The same conditions were used with the EDS system Gresham Scientific Instruments Ltd., Model No. Sirius 10/SUTW.

\subsection{Microhardness measurements}

The microhardness of the microstructure constituents was measured with a Vickers microhardness tester Shimadzu No. 4960 using loads of $100 \mathrm{~g}$ and a loading time of $10 \mathrm{~s}$. The microhardness was measured from the edge of the samples towards the centre.

\subsection{Calculation of CCT diagrams}

For the calculation of the CCT diagrams, a computer programme JMatPro 7.0 [8] was used. Using this programme, CCT diagrams for S355J2 steels with different chemical compositions were calculated. In the calculation, a crystal grain size of 9 , in accordance with the ASTM standard, was taken into account.

\section{Results}

\subsection{Temperature measurements}

The results of the temperature measurements of the hot-rolled steel bar are expressed with a cooling curve (Fig. 1). From that curve, a transformation temperature $\operatorname{Ar}_{1}\left(690^{\circ} \mathrm{C}\right)$ is clearly seen. This indicates the high precision of the measurements.

\subsection{Microstructure analysis}

The microstructure analysis of the sample etched with $2 \%$ Nital performed near the surface with a light microscope revealed a banded microstructure. It consisted of alternating bands of ferrite (white) and pearlite (dark), aligned parallel to the rolling direc- 


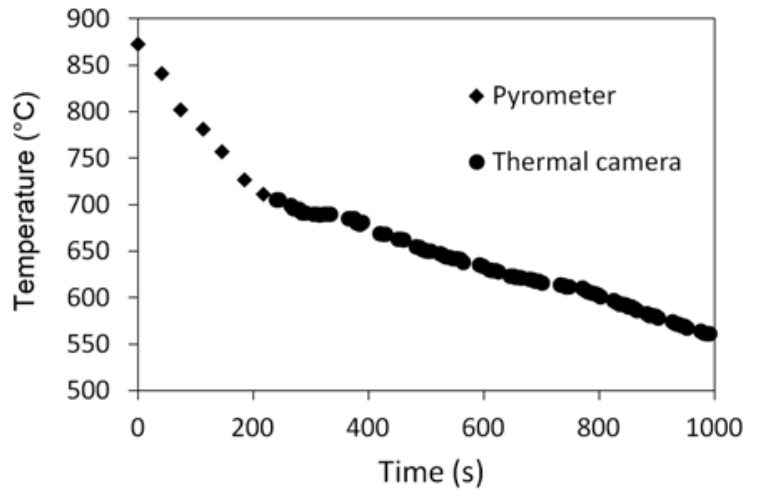

Fig. 1. The cooling curve of a hot-rolled bar obtained with a pyrometer and a thermal camera.
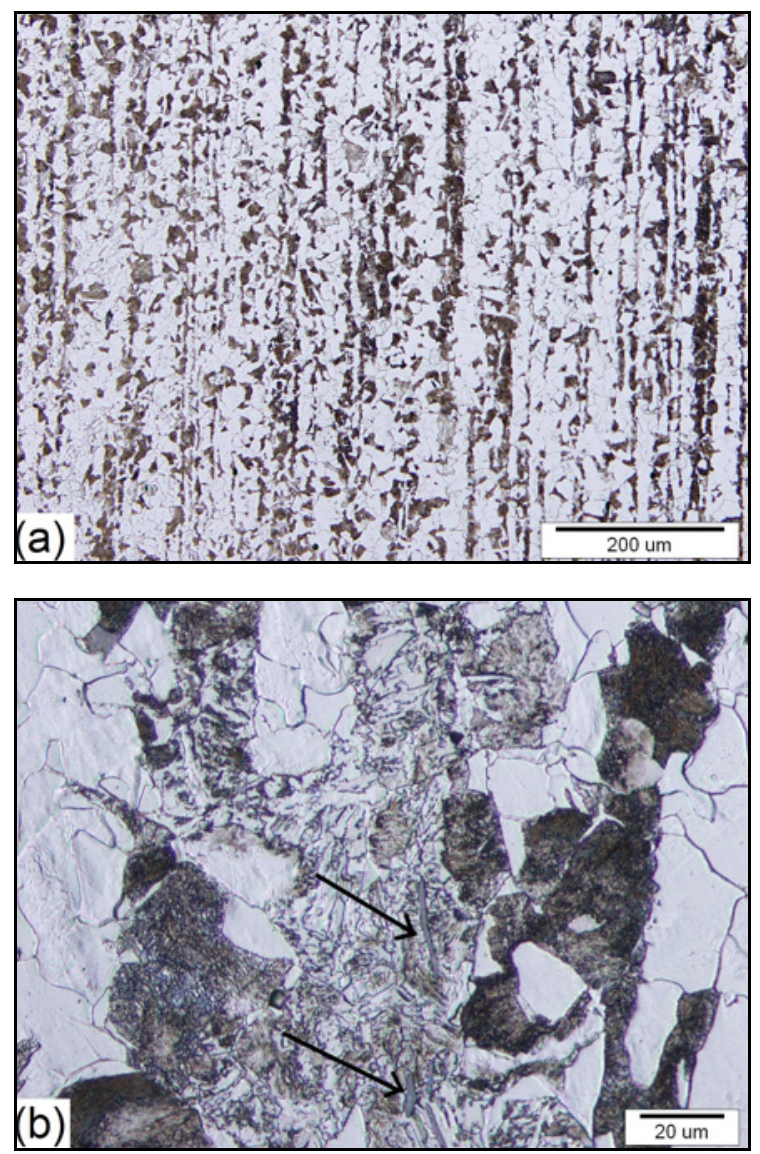

Fig. 2. Banded microstructure (a) near the surface, (b) in the centre of the hot-rolled bar (inclusions are marked with arrows).

tion of the bar (Fig. 2a). However, towards the centre, bainitic-martensitic bands also appeared in the microstructure (Fig. 2b). The proportion of bainiticmartensitic bands increases with the distance from the edge of the sample towards the centre. Figure $2 \mathrm{~b}$ also shows elongated manganese sulphide inclu-
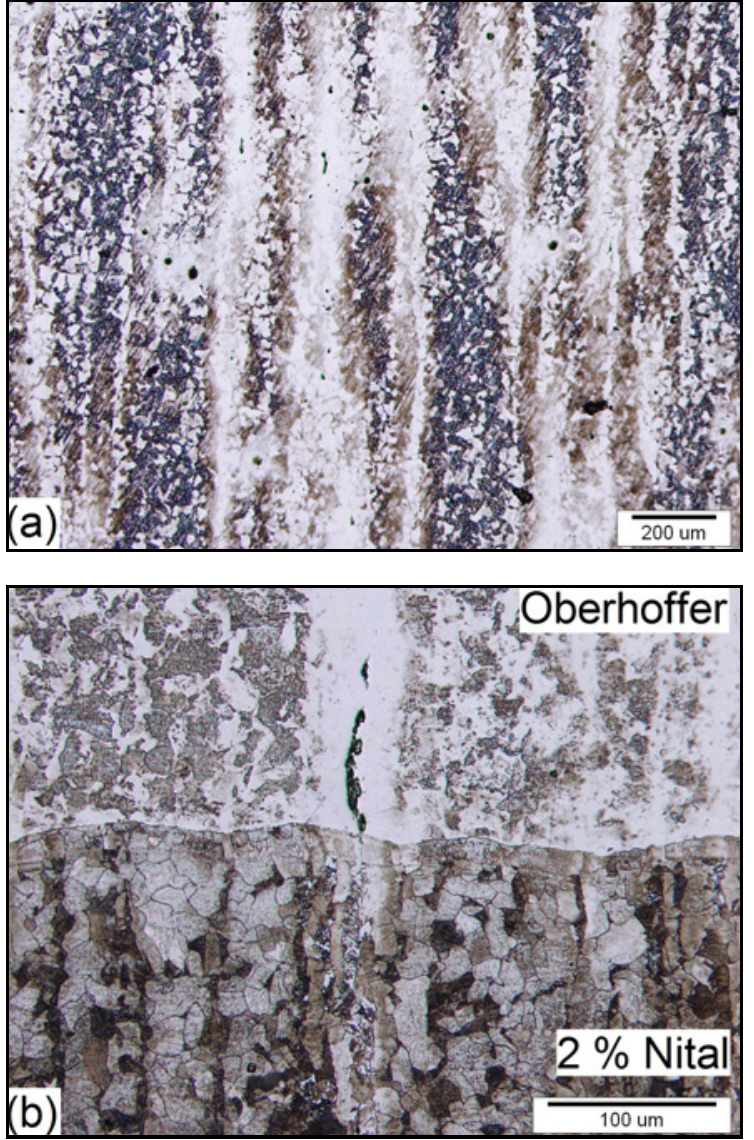

Fig. 3. Phosphorus segregations (a) etched with Oberhoffer reagent (bright bands), (b) etched with Oberhoffer (upper part) and $2 \%$ Nital (bottom part).

sions (marked with arrows). The microstructure observation showed that the MnS inclusions were mostly present in the bainitic-martensitic bands.

The microstructure of the sample etched with Oberhoffer reagent is shown in Fig. 3a. This reagent revealed the phosphorus segregations (bright areas). It is clear that the phosphorus is in the microstructure in alternating bands, parallel to the rolling direction as well. Figure $3 \mathrm{~b}$ shows the microstructure of the sample after etching with $2 \%$ Nital (bottom part of the sample) and Oberhoffer reagent (upper part of the sample). It is clear that the phosphorus segregations coincide with the bainitic-martensitic bands. Again, it was confirmed that the manganese sulphide inclusions were present in the bainitic-martensitic bands, where phosphorus was also detected by the Oberhoffer reagent.

The average results of the EDS analyses in ferritic and bainitic-martensitic bands (Fig. 4) are presented in Table 2. They indicate that in the ferrite the contents of silicon, chromium, manganese, and molybdenum were lower (negative segregations) in comparison to the results of the nominal chemical composition of 
Table 2. Results of EDS analysis (wt.\%)

\begin{tabular}{cccccl}
\hline Site of interest & $\mathrm{Si}$ & $\mathrm{Cr}$ & $\mathrm{Mn}$ & $\mathrm{Mo}$ & $\mathrm{Fe}$ \\
\hline 1 & 0.20 & 0.12 & 1.0 & 0.05 & Bal. \\
2 & 0.38 & 0.18 & 1.6 & 0.19 & Bal. \\
\hline
\end{tabular}

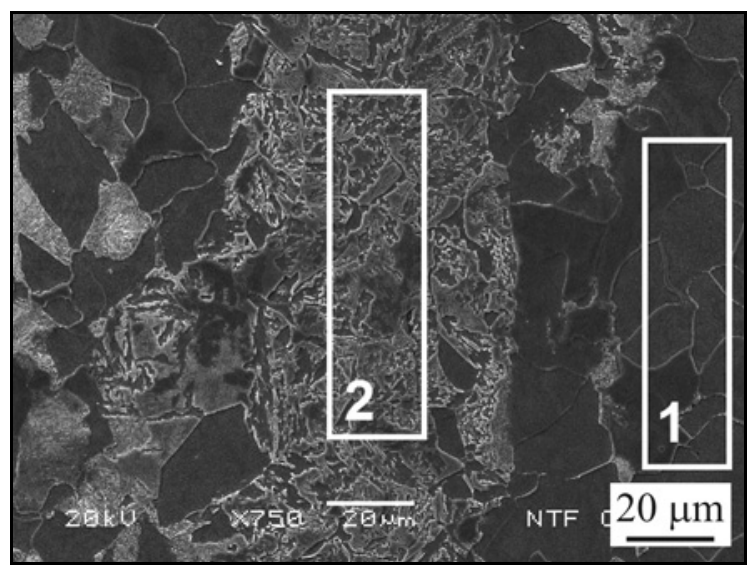

Fig. 4. SEM micrograph of banded microstructure marked with analysed regions.

Ta b le 3. Results of Vickers microhardness measurements

\begin{tabular}{cccccccc}
\hline Distance $(\mathrm{mm})$ & 0.5 & 5 & 10 & 15 & 20 & 25 & 30 \\
\hline HV0.1 & 169.8 & 160.4 & 167.7 & 176.7 & 162.6 & 219.2 & 145.9 \\
\hline
\end{tabular}

the investigated steel listed in Table 1, while in the bainitic-martensitic bands, the contents of these elements were higher (positive segregations). Note that the concentration of phosphorus is below the detection limit of the EDS analysis and, therefore, it was not taken into account.

\subsection{Microhardness}

The results of the microhardness measurements from the edge of the bar towards the centre are presented in Table 3. The lowest hardness value, measured mostly in the ferritic bands, was $138.5 \mathrm{HV}$, while the maximum hardness was 293.0 HV, in the bainitic-martensitic band.

\section{4. $C C T$ diagrams}

Figure 5a shows the CCT diagram of the steel with the nominal chemical composition given in Table 1. However, for comparison, CCT diagrams for the same steel with the chemical composition mea-
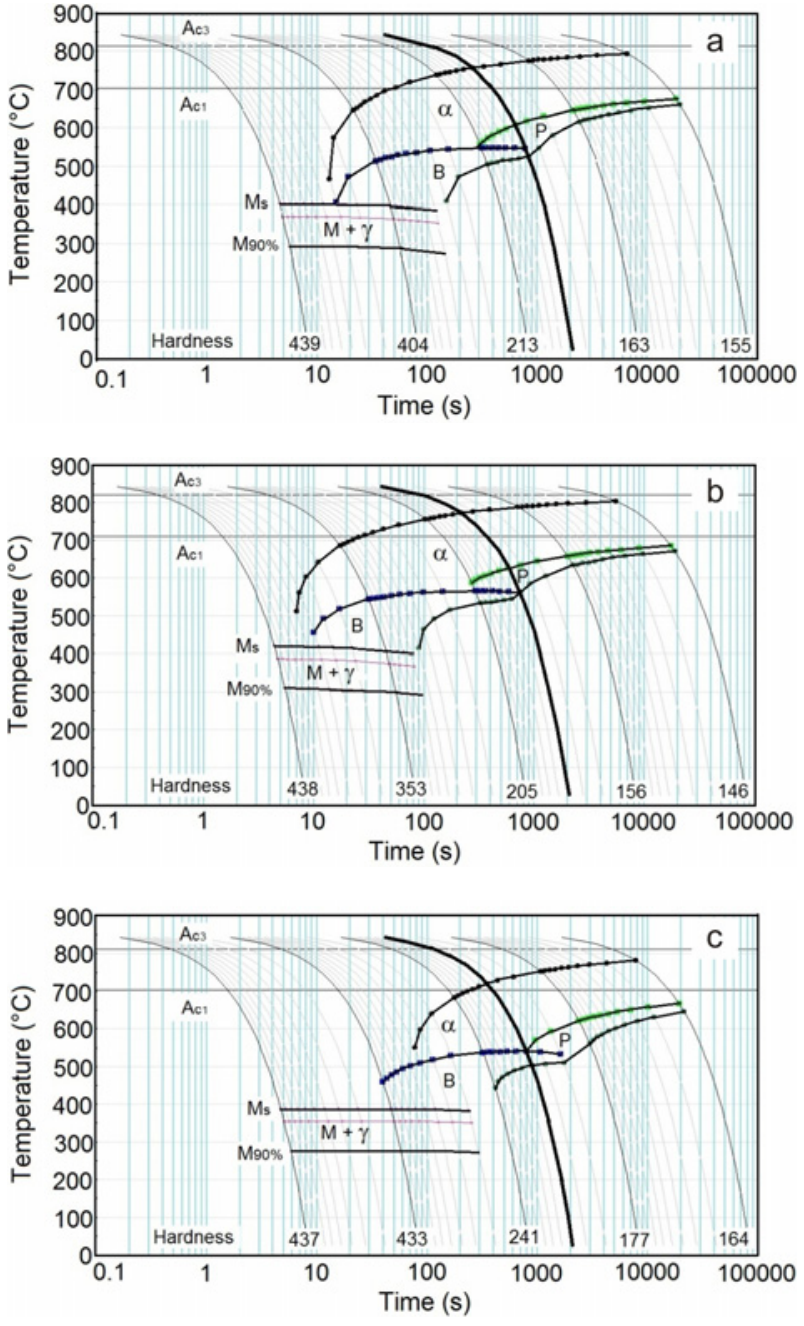

Fig. 5. Calculated CCT diagrams for steel with (a) the nominal chemical composition, (b) with the composition in the negative segregations, and (c) with the composition in the positive segregations.

sured in the negative segregations (Fig. 5b) and positive segregations (Fig. 5c), respectively, were also calculated. The chemical compositions of the steel in the negative and positive segregations were measured with EDS in the ferritic (negative segregations) and bainitic-martensitic bands (positive segregations), respectively.

\section{Discussion}

A banded microstructure is a common phenomenon in rolled-steel products. S355J2 steel is a low-alloy structural steel that is commonly supplied in hot-rolled bars. Since microstructure banding may have a negative effect on the impact properties and subsequent cold-forming operations, it is necessary to minimise it. 
- The microstructure analysis of the metallographically prepared samples after etching in $2 \%$ Nital showed a banded microstructure, which near the surface consisted of ferritic and pearlitic bands (Fig. 2a). However, towards the centre, bainitic-martensitic bands also appeared (Fig. 2b). The portion and the width of these bainitic-martensitic bands increased towards the centre of the bar. The EDS analyses showed higher concentrations of the alloying elements ( $\mathrm{Mn}, \mathrm{Cr}, \mathrm{Mo}$, and $\mathrm{Si}$ ) in the bainitic-martensitic bands (positive segregations) in comparison to the ferritic and pearlitic bands (negative segregations). However, an EDS analysis is not a proper method for the measurement of light elements (e.g., carbon) and elements with a concentration below $0.1 \%$ (e.g., phosphorus); anyway, it is well known that manganese lowers the activity of carbon in austenite and thus, Mn-rich regions would tend to attract carbon from neighbouring areas. Hence, in the Mn-rich regions, an increased concentration of carbon is also expected. While chromium has a similar effect to that of manganese, phosphorus increases the carbon activity, and as a result rejects the carbon from the phosphorus-rich regions [9].

- Phosphorus has a very low equilibrium portion ratio and so it has a strong tendency to segregate during the solidification [9]. Since the concentration of phosphorus is lower than the detection limit of an EDS analysis, the phosphorus segregations were revealed metallographically by using Oberhoffer reagent. From Karl [10], the lower limit of phosphorus detection using Oberhoffer reagent is $0.003 \%$. The microstructure analysis after etching with Oberhoffer reagent showed the phosphorus-rich regions as being brighter (Fig. 3). It was found that the phosphorus segregations coincided with positive segregations of manganese, chromium and molybdenum. Moreover, the elongated manganese sulphide inclusions were also observed in bainitic-martensitic bands with higher concentrations of manganese and phosphorus. This indicates that although the manganese concentrates in the MnS inclusions the austenite around the inclusions still contains enough alloying elements to retard the diffusion-controlled transformation and enable the formation of bainitic-martensitic bands.

- Regarding the activity of carbon, manganese and phosphorus have the opposite effect. Because the concentrations of manganese and chromium in steels are much higher than phosphorus, manganese and chromium have the prevailing effect on the distribution of carbon in austenite. Therefore, it is assumed that regions that are rich in alloying elements $(\mathrm{Mn}$, $\mathrm{Cr}, \mathrm{Mo}$ ) and phosphorus are also rich in carbon, despite the fact that phosphorus increases the carbon activity. On the other hand, the austenite regions depleted in alloying elements and phosphorus contain less carbon. Hence, the austenite region with nega- tive segregations of carbon, phosphorus, and the alloying elements will transform into ferrite during the cooling from the austenite region, while the austenite regions with positive segregations will later transform into pearlite. In this way, a secondary, banded microstructure of ferrite and pearlite bands is developed.

- Additionally, the alloying elements (Mn, Cr, Mo, $\mathrm{Si})$ have a strong effect on the hardenability since they move the CCT diagram to the right. Moreover, it is also known that phosphorus also significantly enhances the hardenability $[6,11]$, and can cause both quench cracking and quench embrittlement [6]. Since the concentration of alloying elements as well as phosphorus and carbon increases towards the centre of the ingots, the proportion of bainitic-martensitic bands is higher towards the centre of the hot-rolled bar. Moreover, the concentration of alloying elements and phosphorus in some austenite regions was high enough for a critical cooling rate to be achieved and, consequently, martensite, as well as bainite, was formed despite lower cooling rate in the centre of steel bar.

- The formation of bainitic-martensitic bands can be explained with the calculated CCT diagrams: a CCT diagram with the nominal steel composition given in Table 1; a CCT diagram with the composition measured in the negative segregations with a lower concentration of $\mathrm{Mn}, \mathrm{Cr}, \mathrm{Si}$, and Mo (Table 2, Site of Interest 1); and a CCT diagram with a composition measured in the positive segregations with an increased concentration of $\mathrm{Mn}, \mathrm{Cr}$, Si, and $\mathrm{Mo}$ ( $\mathrm{Ta}-$ ble 1 , Site of Interest 2). The increased concentration of alloying elements retards the diffusion-controlled transformation, and therefore the ferritic and pearlitic regions move to a higher timing in comparison to the CCT diagram of steel with the nominal composition and even more compared to the CCT diagram of the steel with the composition of negative segregations. In addition, the martensite start temperature $\left(M_{\mathrm{S}}\right)$ is lowered with an increased concentration of alloying elements. Hence, at a normal cooling rate of approximately $0.4^{\circ} \mathrm{C} \min ^{-1}$ (bold line in Fig. 5) in regions with increased concentration of alloying elements (positive segregations), some bainite in addition to the ferrite is also expected (Fig. 5c), while in the regions with a lower concentration of alloying elements (negative segregations) only ferrite and some pearlite can form (Fig. 5b). However, in this calculation, the changes in the concentration of carbon and phosphorus were not taken into account since they could not have been analysed with EDS. It is known that both elements significantly increase the hardenability of steel since they move the CCT diagram further to the right, to a higher timing, and as such enable the formation of martensite and, therefore, the formation of bainitic-martensitic bands at the same, and with an even slower, cooling rate in the centre of 


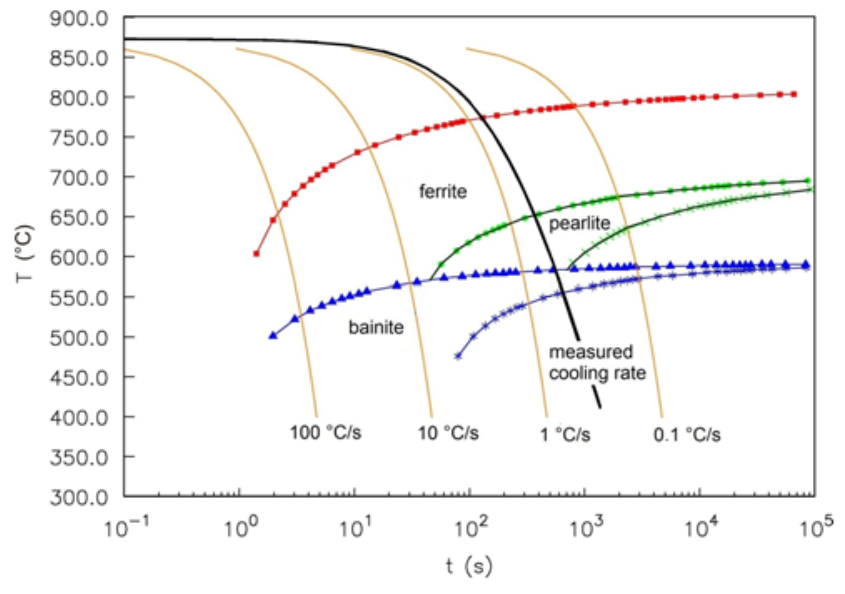

Fig. 6. Calculated CCT diagram of S355J2 steel with measured and extrapolated cooling curves.

the steel bar. This shows again the importance of revealing the phosphorus segregations since phosphorus can cause alternating bands of different microstructural constituents with different mechanical properties (Table 3).

- Taking into account the real cooling rate determined by a temperature measurement of the steel bar with a pyrometer and a thermal camera after hotrolling processes, a microstructure of steel with homogeneous chemical compositions can be predicted. Namely, the measured cooling rate, which was extrapolated to lower temperatures, was used as an input for the JMatPro software, and a CCT diagram of the steel with nominal chemical compositions was calculated (Fig. 6). The bold cooling curve in the CCT diagram shows that mainly ferrite, pearlite, and very small amount of bainite were expected in the microstructure if the chemical composition of the steel was to be homogeneous. The transformation temperatures of the austenite into ferrite, pearlite, and bainite were also determined and were found to be 775,650 , and $570{ }^{\circ} \mathrm{C}$, respectively.

\section{Conclusions}

In this paper, we explain the development of the banded microstructure in hot-rolled S355J2 steel. Aligned bands of ferrite and pearlite were observed; however, towards the centre of the steel bar bainitic-martensitic bands were also present. Their portion and width increased when moving from the edge of the bar towards the centre. The EDS analyses showed a higher concentration of alloying elements $(\mathrm{Mn}, \mathrm{Cr}$, $\mathrm{Mo}$, and $\mathrm{Si}$ ) in the bainitic-martensitic bands in comparison to the ferritic bands. However, the EDS analyses did not show the presence of phosphorus because the quantity was below the detection limit of our EDS detector. Phosphorus can be very detrimental since it can be responsible for banding and it can also cause both quench cracking and embrittlement. The etching with Oberhoffer reagent revealed bands of phosphorus segregations that coincided with positive segregations of the alloying elements. The calculated CCT diagrams of steel with chemical compositions of positive segregations did not provide evidence for martensitic transformations at a normal cooling rate. Therefore, the formation of martensite can be attributed to the increased concentration of carbon and phosphorus, which were not taken into account in the calculation of the CCT diagrams. Carbon and phosphorus retard the diffusion-controlled transformation and thus significantly increase the hardenability of the steel. A real cooling curve put in the CCT diagram of S355J2 steel with a homogeneous chemical composition showed that the microstructure would consist of ferrite, pearlite, and a small amount of bainite. The transformation temperatures of the austenite into ferrite, pearlite, and bainite would be 775,650 , and $570^{\circ} \mathrm{C}$, respectively.

\section{References}

[1] Zorc, B., Bernetič, J., Nagode, A.: Eng. Fail. Anal., 40, 2014. p. 8. doi:10.1016/j.engfailanal.2014.02.014

[2] Krauss, G.: STEELS: Processing, Structure and Performance. Ohio, ASM International 2005.

[3] Majka, T. F., Matlock, D. K., Krauss, G.: Metall. Mater. Trans. A, 33, 2002, p. 1627. doi:10.1007/s11661-002-0172-8

[4] Krebs, B., Germain, L., Gouné, M., Hazotte, A.: IJMR, 102, 2011, p. 200. doi:10.3139/146.110467

[5] Yadegari, S., Turteltaub, S., Suiker, A. S. J., Kok, P. J. J.: Comp. Mater. Sci., 84, 2014, p. 339. doi:10.1016/j.commatsci.2013.12.002

[6] Roberts, G., Krauss, G., Kennedy, R.: Tool Steels. 5th Edition. Ohio, ASM International 1998.

[7] Schumann, H.: Metallographie. Leipzig, VEB DVG 1987.

[8] JMatPro 7.0. Occam Road, United Kingdom, Sente Software Ltd.

[9] Krauss, G.: Metall. Mater. Trans. B, 34, 2003, p. 781. doi:10.1007/s11663-003-0084-z

[10] Karl, A.: Prakt. Metallogr., 15, 1978, p. 469.

[11] Jacobs, F. A., Kraus, G.: J. Heat Treating, 2, 1981, p. 139. doi: $10.1007 / \mathrm{BF} 02833230$ 